\title{
Compliance of pedometer-derived physical activity recommendations and step accumulation patterns in Chilean children from low-income areas \\ Cumplimiento de las recomendaciones de actividad física derivadas del podómetro y patrones de acumulación de pasos en niños chilenos de áreas de bajos ingresos \\ Damian Chandia-Poblete, Andrea Cortinez-O’Ryan, Constanza Ulloa-Lopez, Nicolas Aguilar-Farias \\ Universidad de La Frontera (Chile)
}

\begin{abstract}
Background: Device measured physical activity (PA) allow better understanding on how PA is accrued during days. The purpose of this study was to describe pedometer-derived PA levels and patterns by gender in a population of Chilean children. Methods: 100 children were randomly selected from two low-income neighborhoods in Santiago, Chile. PA was measured with a wrist-worn pedometer for 7 consecutive days. Steps were summarized as total steps per hour and steps per day. PA hourly-patterns were compared across subgroups by age, gender, residence type and nutritional status. Results: 85 participants provided valid data (40 boys, 7.9 $\$ 2.64$ years, $47.8 \%$ overweight/obese). On an average day, children accumulated $11692.8 \pm 6061.8$ steps with no differences between sexes $(\mathrm{p}=0.14)$. However, boys accumulated more steps in the morning and lunchtime than girls. Only $35.3 \%$ of the sample met PA guidelines (active), with no differences by sex ( $\mathrm{p}=0.39$ ). Active children in weekdays were more likely to meet the guidelines in weekend days (adjusted OR: 4.70, CI 95\% 1.67-13.20) than those inactive in weekdays. Conclusion: PA guidelines compliance was relatively low. Step accumulation patterns differed between and within days including differences by gender in the morning and lunch time. This information may be used for designing feasible and equitable strategies for increasing the chances for meeting PA recommendations in both girls and boys.

Keywords: pedometer, physical activity assessment, community-based research, health behavior.
\end{abstract}

Resumen. Antecedentes: los métodos objetivos para medir la actividad física (AF) permiten una mejor comprensión de cómo se acumula la AF durante días. El propósito de este estudio fue describir los niveles y patrones de AF derivados del podómetro en una población de niños chilenos. Métodos: 100 niños participaron de dos barrios de bajos ingresos seleccionados al azar en Santiago de Chile. AF se midió con un podómetro de pulsera durante 7 días consecutivos. Los pasos se resumieron como pasos totales por hora y pasos por día. Los patrones de AF por hora se compararon entre los subgrupos

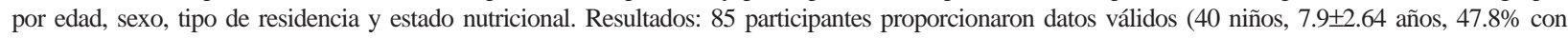
sobrepeso / obesidad). En un día normal, los niños acumularon 11692.8 \pm 6061.8 pasos sin diferencias entre sexos ( $\mathrm{p}=0.14)$. Sin embargo, los niños acumularon más pasos en la mañana y mediodía que las niñas. Solo el 35.3\% de la muestra cumplió con las recomendaciones de $\mathrm{AF}$ (activo), sin diferencias por sexo $(\mathrm{p}=0.39)$. Los niños activos en los días de semana tenían más probabilidades de cumplir con las recomendaciones en los días de fin de semana (OR ajustado: 4.70, IC 95\% 1.67-13.20) que los inactivos en los días de la semana. Conclusión: El cumplimiento de las recomendaciones de AF fue relativamente bajo. Los patrones de acumulación de pasos difieren entre y durante el día, incluyendo diferencias según sexo en relación a la acumulación de pasos en la mañana y almuerzo. Esta información puede ser utilizada para diseñar estrategias equitativas para aumentar las posibilidades de cumplir con las recomendaciones de AF tanto para niñas como para niños.

Palabras clave: podómetro, evaluación de la actividad física, investigación basada en la comunidad, comportamiento saludable.

\section{Introduction}

The evidence have consistently supported the numerous health benefits of physical activity (PA) in children (Leinaar, Alamian, \& Wang, 2016; Steinbeck, 2001; Strong etal., 2005), including benefits on cognitive processes (Tandon et al., 2016), socialization, self-esteem and self-concept (Rhodes \& Smith, 2006). PA is a determining factor in the energy consumption, therefore, it is essential for maintaining energy balance and weight control (Westerterp \& Plasqui, 2004). These benefits are reflected in a positive dose-response relationship between PA and health (Janssen \& Leblanc, 2010). To be optimally benefited from PA, it is recommended for children to perform at least 60 minutes of moderateto-vigorous PA (MVPA) per day (World Health Organization, 2010).

Most countries in Latin America are lacking in evidence about PA levels and compliance of PA recommendations in young population (Hallal et al., 2012). Most evidence have been mainly derived from selfreport instruments (Aguilar-Farias et al., 2018; Bauman et al., 2012). However, objectives methods for measuring PAbased on accelerometers and pedometers are more accurate to determine total PA volumes (Strath, Pfeiffer, \& Whitt-Glover, 2012). Objective tools for measuring PA are relatively more expensive and require trained researchers for data analysis compared with self-report methods, which may partially explain limited data availability derived from these devices in Latin America. Despite this, some Latin American countries such as Colombia, Brazil and Mexico have reported PA data with accelerometers at population level in children (da Silva et al., 2014; Katzmarzyk et al., 2015; Medina, Barquera, Katzmarzyk, \& Janssen, 2015). Another alternative is the use of pedometers as they deliver PA data as measured in total steps accumulated during a given time (e.g. minute, hour, day). Pedometers not only measure PA in an objective, non-invasive and accurate fashion, but also at lower cost than most accelerometers (Butte, Ekelund, \& Westerterp, 2012). It is well-recognized that walking is a simple, natural and accessible option for being physically active within a day (CristiMontero, 2013). Therefore, PA recommendations can also be expressed in recommended steps per day (13000 steps/day for boys, 12000 steps/day for girls) (Rowlands \& Eston, 2005). Using this principle, a study conducted in Chile in 6-9 aged school children reported that 33\% of boys and $15 \%$ of girls met the PA recommendations as measured with pedometer in week days (Moreno, Cano, Orellana, \& Kain, 2015). While, only $17 \%$ of boys and $9 \%$ of girls met the PA recommendation on weekend days (Moreno et al., 2015). These gender discrepancies have been observed in self-reported PA in Chilean children as well (Aguilar-Farias et al., 2016; Aguilar-Farias et al., 2018).

Objective devices provide higher resolution than self-report methods. Some pedometers, for example, not only provide total steps per day, but also they inform how these steps were accrued during an hour, day or week (i.e. PA patterns). Studies have reported differences on daily PA patterns and volumes between sexes (Vander Ploeg, Wu, McGavock, \& Veugelers, 2012), independent of nutritional status (Deforche, De Bourdeaudhuij, D’Hondt, \& Cardon, 2009), as well as, have reported differences in seasonal patterns (Kolle, SteeneJohannessen, Andersen, \& Anderssen, 2009), in class periods and out of class (Aguilar-Farias, Martino-Fuentealba, \& Espinoza-Silva, 2015; Beck, Chard, Hilzendegen, Hill, \& Stroebele-Benschop, 2016), and variations in school and weekend days (Aguilar-Farias et al., 2015; Steele et al., 2010). However, these variations have been different across nations. Therefore, objectively measured PA patterns may facilitate detection of opportunity windows for generating targeted actions for children, particularly for this age group as they are in a critical period before starting adolescence in which PA, generally, start to decrease in 
both genders (Jago et al., 2018).

Due to the limited evidence available with device measured PA in Chile and their potential benefit to better understand how PA is accumulated within a day or week (Aguilar-Farias et al., 2016), the purpose of this study was to describe compliance of pedometer-derived PA recommendations and step accumulation patterns in a population of children from two low-income neighborhoods of the Region Metropolitana de Santiago, Chile.

\section{Methods}

\section{Design}

The study sample of this cross-sectional study comes from randomly selected low-income neighborhoods in the Peñalolen district of Santiago, Chile between August-October 2014. A low-income neighborhood was defined as part of the two lowest income quintiles in Chile. Neighborhood selection considered environmental and socioeconomic features described elsewhere(Cortinez-O’Ryan, Albagli, Sadarangani, \& Aguilar-Farias, 2017). The participants were a objectively measured subsample of the pre-post trial called «Juega en tu Barrio» (Play in your Neighborhood) consisting in a play street program implemented on weekdays, for promoting PA among 4-to-12 year old children of low socioeconomic status (Cortinez-O'Ryan et al., 2017). Baseline data obtained from the intervention and control neighborhoods were analysed in the current study to avoid the intervention's effect.

During data collection, each child and their family were visited three times for 1) providing information and recruitment, 2) signing written informed consent, completing a questionnaire and attaching a wrist-worn pedometer, and 3) collecting the wrist-worn pedometer. The study received approval from the Ethics Committee of the Universidad Metropolitana de Ciencias de la Educacion, Chile.

\section{Measurements}

Demographic data were obtained from the questionnaire completed by each participant's responsible adult. Anthropometric variables (weight and height) were obtained with a portable measuring station (Seca 220, seca Deutschland, Germany). Body mass index (BMI) was estimated with weight in kilograms divided by height in meters squared. Nutritional status was classified as underweight, normal, overweight and obese based on BMI-for-age from the World Health Organization (WHO) reference standards (World Health Organization). Participants living in both, houses (61\%) and apartments (39\%) were recruited during August and September 2014. The houses faced the street and without or limited backyards. Apartments were located in gated four-story buildings with some protected open space for play.

\section{Physical activity}

Pedometer-determined PA was assessed with Movband (Movable, USA), a wrist-worn accelerometer that was placed on the participant's non-dominant side. The device has shown excellent reliability and concurrent validity when compared with other widely used accelerometers (Barkley, Rebold, Carnes, Glickman, \& Kobak, 2014; Fadel et al., 2015). Participants wore the Movband for 7 consecutive days and were asked to remove the pedometer only in water-based activities. Movbands were charged, synchronized and downloaded on the same computer to avoid time mismatches. Data were extracted in total steps per hour as allowed on the Movable online software. The participants were asked to complete a logbook every day to record their pedometer wearing time and waking hours.

\section{Pedometer data reduction}

Data from logbooks weremerged with pedometer records for deleting non-wearing time. Pedometer-determined PA was considered valid if the participant wore the device for at least 10 hours in 3 weekdays and 1 weekend day (Rich et al., 2013). Steps were summarized as total steps per hour as well as total steps per day. Mean steps per hour on average day, weekdays and weekends for each participant were also calculated for comparisons across subgroups. Mean total steps on an average day were calculated as follows: ((Mean total steps in weekdays x 5) + (mean total steps in weekend days x 2) / 7). While mean total steps per weekday and weekend day were also calculated in a similar method, but only including their respective days. Participants who met the pedometer-determined PA recommendations or 'physically active' were defined as those children that recorded at least 13000 steps per day for boys, and 12000 steps per day for girls (Rowlands \& Eston, 2005). For the PA hourly-pattern analysis, mean total steps per hour on an average day, average weekday and average weekend day were calculated for each participant and compared across subgroups by age, gender, residence type and nutritional status.

\section{Statistical analysis}

Data were tested for normality with Shapiro-wilk. Means and standard deviation were used for describing normally distributed data, while median and quartiles were used for non-normally distributed data. Categorical data were shown as percentages. Differences between sexes for continuous data were assessed with Student T-test and multivariate Kolgomorov-Smirnov test depending on their distribution, while categorical data were assessed with chi-square test. Multivariate regression was used to assess the association for both 1) mean steps per day (average day, weekday, weekend day), and 2) PArecommendation compliance with gender, age, nutritional status, number of siblings, number of friends and residence type, respectively. All statistical analyses were performed using Stata 13.0 (StataCorp. College Station, TX, USA) and $\mathrm{p}<0.05$ was considered statistically significant.

\section{Results}

In total 100 children were measured, out of which 85 (40 boys) provided complete and valid data for pedometer-determined PA. The mean age was 7.9 years (SD: 2.64, range 3-13) and $47.8 \%$ of the sample was overweight. No differences between sexes were observed for age, BMI and nutritional status. Sample characteristics are displayed in Table 1.

\section{Step accumulation per day}

On an average day children accumulated $11692.8 \pm 6061.8$ steps with no differences between sexes $(\mathrm{p}=0.14$, Table 2$)$. No statistical differences were found either for mean total steps on weekdays ( $\mathrm{p}=0.13$ ) and on weekends ( $\mathrm{p}=0.45$ ) between sexes. Also, no differences were

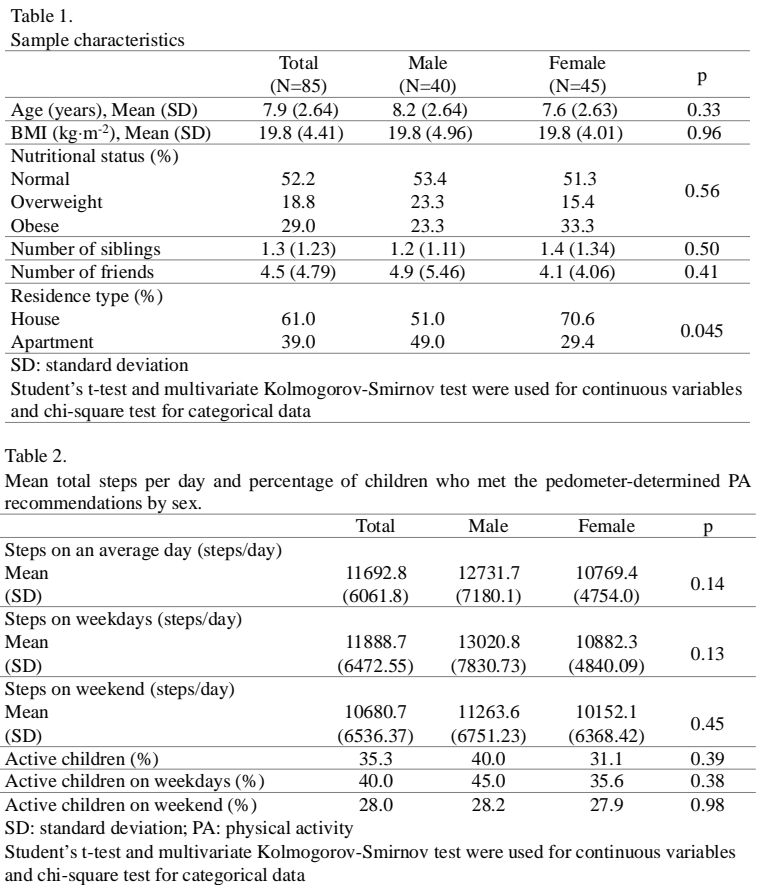


observed between mean total steps on weekdays and weekend days (11888.7 \pm 6472.6 vs $10680.7 \pm 6536.4$ steps/day; $\mathrm{p}=0.23$ ).

\section{Compliance of pedometer-derived PA recommendations}

Only $35.3 \%$ of the sample met the recommendation for pedometerdetermined PA on an average day, with no statistical differences between weekdays and weekend days $(\mathrm{p}=0.10)$. Also, despite more boys than girls met the PArecommendation, no statistical difference was observed between them ( $\mathrm{p}=0.39$ ).

When using multivariate regression analysis for estimating odds ratio for meeting pedometer-derived PArecommendations, no differences were found when adjusting by gender, age, nutritional status, number of siblings, number of friends and residence type. However, those children who met the PA recommendations in weekdays were more likely to meet the guidelines in weekend days (adjusted OR: 4.70, CI 95\% 1.6713.20) than those inactive in weekdays.

\section{Step accumulation patterns}

Step accumulation patterns were different in some hours of the day between boys and girls (Figure 1) on an average day, weekday and weekend days. Overall, step accumulation patterns on an average day fluctuated during the day with a peak at lunch time (1055.8 \pm 475.8 steps/hour) and steady decline throughout the afternoon (Figure 1). On an average day, step accumulation patterns differed between sexes with boys accruing more steps per hour than girls in the morning at 8:00-8:59 (514.1 \pm 415.9 vs 274.8 \pm 278.4 steps/hour, $\mathrm{p}=0.002$ ), 9:00-9:59 (566.3 \pm 397.4 vs $408.5 \pm 320.0$ steps/hour, $\mathrm{p}=0.046$ ), and at lunch time from 13:00-13:59 (1195.9 \pm 512.1 vs 931.3 \pm 407.4 steps/hour, $p=0.01$ ) to $14: 00-14: 59$ (922.0 \pm 438.7 vs $676.7 \pm 336.7$ steps/hour, $\mathrm{p}=0.005)$ (Figure2).

Step accumulation patterns during some hours of the day were statistically different when comparing these patterns between weekdays and weekend days in the total sample (Figure 3). Children on weekdays had higher step accumulation per hour than weekend days from 6:00 to 10:59, and 13:00-13:59. While more steps per hour were observed from 22:00 to 00:59 in weekend than weekdays. Mean differences in steps per hour between weekdays and weekend ranged from -314.9 steps/ hour at 23:00-23:59 $(\mathrm{p}=0.001)$ to 348.9 steps/hour at 13:00-13:59 $(\mathrm{p}=0.003)$.
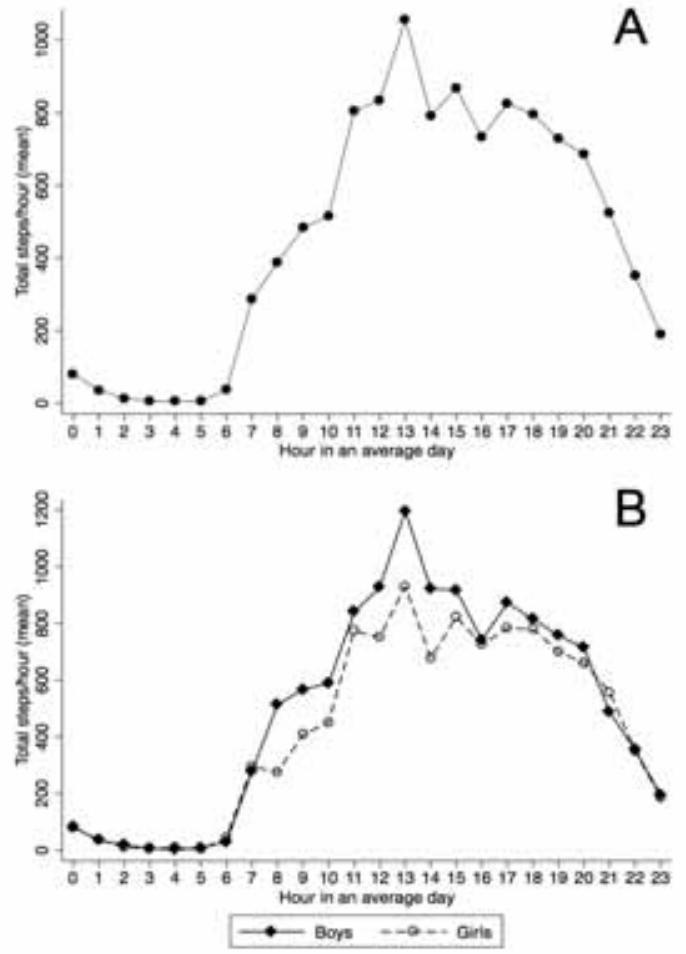

Figure 1. Pedometer-determined physical activity patterns in the total sample (A), and boys and girls (B) on an average day.

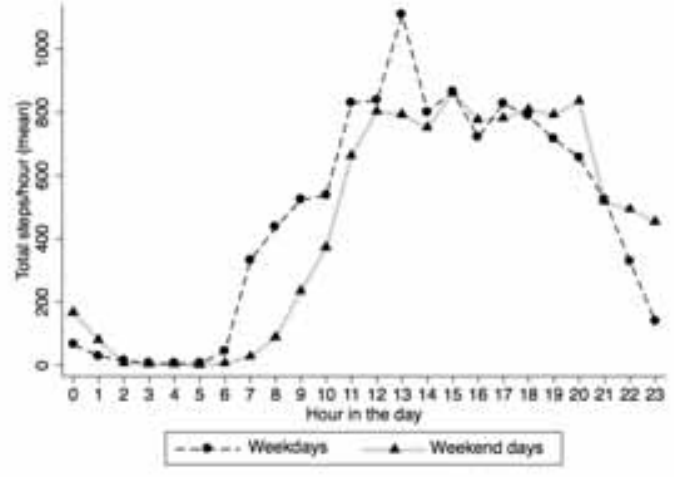

Figure 2. Pedometer-determined physical activity patterns in children on an average weekday and average weekend day.
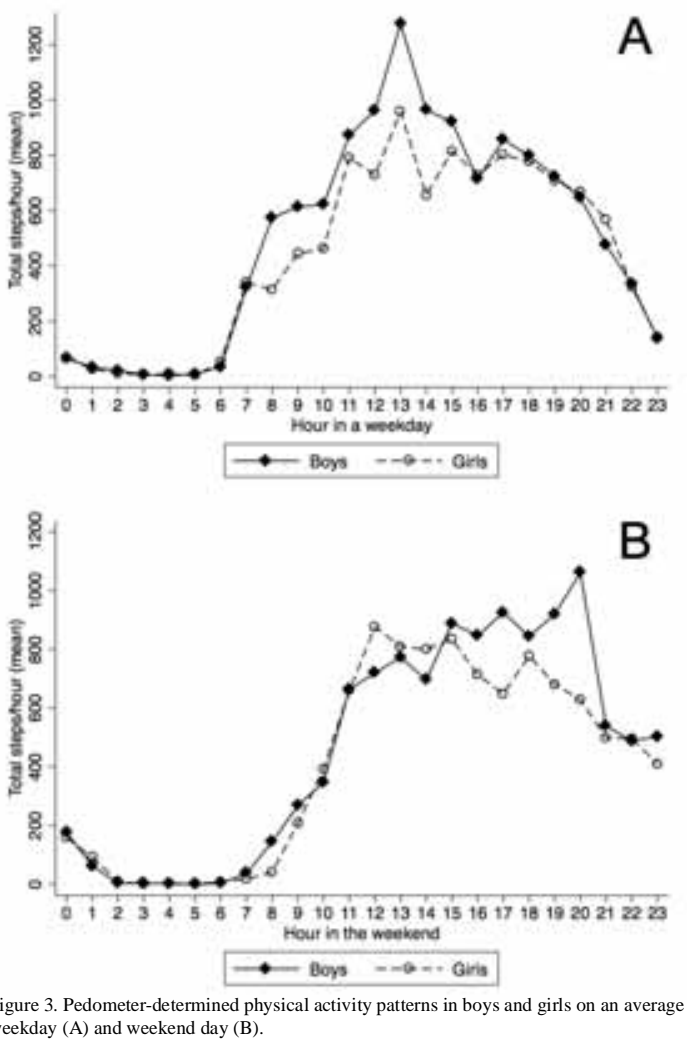
weekday (A) and weekend day (B).

Patterns of step accumulation per hour in weekdays by sex showed similar distribution to those described on an average day (Figure 4). In weekdays, boys accumulated more steps per hour than girls at 8:008:59 (574.2 \pm 450.00 vs $314.0 \pm 313.20$ steps/hour, $\mathrm{p}=0.003$ ), 12:0012:59 (961.8 \pm 464.85 vs 728.1 \pm 414.13 steps/hour, $\mathrm{p}=0.016)$ ), 13:0013:59 (1275.7 \pm 553.74 vs $957.4 \pm 427.08$ steps/hour, $\mathrm{p}=0.004$ ), and 14:00-14:59 (963.1 \pm 520.80 vs $656.1 \pm 371.40$ steps/hour, $\mathrm{p}=0.002$ ). Hourly PA patterns on weekend days were different between boys and girls only at 20:00-20:59 (1061.5 \pm 992.18 vs 628.2 \pm 682.57 steps/hour, $\mathrm{p}=0.02$ ), which corresponds to the highest accumulation of steps/hour on the day for boys.

\section{Discussion}

The present study described compliance of pedometer-derived PA recommendations and step accumulation patterns in children of two low-income neighborhoods in Chile. In our study, the average of accumulated steps per day was 11692, which is lower than reported in other studies in similar age groups from other countries (Cox, Schofield, Greasley, \& Kolt, 2006; Craig, Cameron, Griffiths, \& Tudor-Locke, 2010; Duncan, Al-Nakeeb, Woodfield, \& Lyons, 2007; Rosa et al., 2011), but higher than those observed in another Chilean sample of 
adolescents (Parra Saldías, Vega, Fernández, \& Ramírez, 2018).

The significant differences reported in international studies that have favored boys (Beltrán Carrillo et al., 2017; Duncan et al., 2007; Gao, Wang, Lau, \& Ransdell, 2015) contrast with the lack of statistical difference in mean accumulated daily steps between girls and boys in our study (12731.7 vs 10769.4, p=0.14). However, the absolute difference observed (2000 steps/day approx.) was similar to that reported in other study conducted in Canadian population (boys 12259 vs girls 10906) (Craig et al., 2010). This may be partially explained by the wide dispersion of step accumulation patterns in both sexes as well as the relatively small sample size of our study. Another aspect that could have affected these results is that the sample of the study comes from low-incomeneighborhoods. In Chile, it has been observed that children attending public schools and live in low socioeconomic neighborhood, have less physical education classes, organized sports and reduced access to better quality infrastructure than children of higher socioeconomic level (Aguilar-Farias et al., 2016). These precarious conditions for performing PA may be affecting negatively in similar grade both girls as boys.

In our sample, no differences were observed in PA recommendation compliance rates when comparing and adjusting by different sociodemographic factors, including age. This may be partially explained as the participants were preadolescents and not adolescents in which PA decline and gender differences are exacerbated (Dumith, Gigante, Domingues, \& Kohl, 2011), Efforts must be kept to ensure that children should engage and enjoy PA not only in school, but also in out-ofschool hours, as participation in PA and perceptions about physical education tend to decrease with age (Brooke, Corder, Griffin, \& van Sluijs, 2014; Carcamo-Oyarzun, Wydra, Hernandez-Mosqueira, \& Salazar, 2017; Jago et al., 2018). Only a third of the sample met the PA recommendations, with lower compliance in weekend days (27.9\% boys and $28.2 \%$ girls) than weekdays ( $45.0 \%$ boys and $35.6 \%$ girls) as similarly shown in other studies (Moreno et al., 2015; Vander Ploeg et al., 2012). These findings may suggest that the school environment promotes higher PA levels in children than homes or neighborhoods under this context as similarly shown in another study conducted in Chile(Godard, Román, Rodríguez, Leyton, \& Salazar, 2012). Therefore, it may be pertinent to focus investments on out-of-school PA programs for providing opportunities in disadvantaged neighborhoods (CortinezO'Ryan et al., 2017), especially when considering that inactive children during weekdays are very likely to remain inactive on weekend days.

On an average day, higher step accumulation per hour was observed in boys than girls during the morning (8:00 - 10:00) and lunch time (13:00-15:00). These differences were also observed between weekdays and weekend days in the total sample, being active transportation to school and active play after lunch in weekdays (e.g. football in boys) possibly major contributors of this disparity. Studies in other countries have reported similar PApatterns to those observed in our study (Beltrán Carrillo et al., 2017; Goodman, Page, Cooper, \& International Children’s Accelerometry Database, 2014; Vander Ploeg et al., 2012). For example, a study conducted in China reported that boys were more active before school than girls, but no differences were observed at lunch time as in our study (Gao et al., 2015). More comparable findings were reported by Beltran-Carrillo et al (2017) in a sample of Spanish adolescents showing that boys were more active than girls before and during school hours. The step accumulation patterns described in this study provide relevant information for both reinforcing existing behaviors and creating new strategies to enhance these «more active» periods (e.g. safe routes, active breaks) (DiMaggio, Frangos, \& Li, 2016; Hyndman, Benson, Ullah, \& Telford, 2014). At the same time, these patterns clearly showed certain temporary spaces not only within a day but also in particular days where low PAlevels were observed. These temporary spaces (i.e. lunch break) may be used for providing more opportunities for being more physically active at school or homes.

Chile, as it is located at the south of the Americas, meets special features related to the long hours of exposure to sunlight in spring and summer periods. The number of accumulated steps per hour in late hours (after $7 \mathrm{pm}$ ) was similar to those observed in other countries that have implemented daylight saving (Goodman et al., 2014) and different to those reported in countries located closer to the Ecuator (Tucker \& Gilliland, 2007). In line with these findings, Goodman et al. suggested that daylight saving could be evaluated as a public health strategy, due to its impact on the increment of PA levels in children from countries that implement compared to those who do not implement daylight saving (Goodman et al., 2014).

\section{Strengths and limitations}

There are other studies in Chile that have measured PA with pedometers, but to our knowledge, this is the first where the sample was obtained from low-income neighborhoods and then randomly selected to participate in the measurement. Pedometers were worn in the participants' wrists, offering excellent compliance. Additionally, as these devices did not display the step count, it seems unlikely that PA behaviors may have been influenced by their use. The pedometer used in this study had memory, thus, it was not necessary to request children registering daily step count and reset the device every day, reducing sources of bias (i.e. participant's memory, acceptability). Despite the strengths, our study was not exempt of limitations. The sample size was relatively small, but comparable to other exploratory studies (Deforche et al., 2009; Dorsey, Herrin, \& Krumholz, 2011; Godard et al., 2012). PA patterns were measured on a single time frame during spring; therefore, we were not able to measure seasonal changes or trends within a same season. Despite this aspect was not part of our main goal, this may be considered in further studies, especially in countries with marked seasonal changes in terms of temperature, rain fall and sunlight exposure.

\section{Conclusion}

Only a third of the participants met the pedometer-determined PA recommendation on an average day, reinforcing the need for effective strategies to improve these figures. Children who met the PA recommendations in weekdays were more likely to meet the guidelines in weekend days than those inactive in weekdays, suggesting that physical behaviours tend to be stable in this age group. Hourly patterns showed that accumulated steps during early hours of the morning and lunchtime in school days play a key role in increasing PA during these days. In addition, boys accumulated more steps than girls during those periods that may reflect in some extent gender disparities in terms of active transportation, and use of playgrounds for engaging active play in activities such as football. This information may be used for designing equitable strategies for increasing the chances for meeting PA recommendations in both girls and boys.

\section{Acknowledgments}

Our team is particularly grateful to the children and their families who gave their time and support uninterestedly. The authors would like to thank the research assistance of Cristian Arias, Gerson Avendaño, Aldo Reyes, Daniel Chabur and Javier Nieto. We thank the Municipalidad de Peñalolén and CicloRecreoVía for their support during the execution of the fieldwork.

This research was funded by the Chilean National Fund for Research and Development in Health, FONIS. Grant number: EVS-13I0052. DCP, CUL and NAF were supported by CONICYT FONDECYT 11160720 and the Direccion de Investigacion, Universidad de La Frontera.

Conflict of interest: none 


\section{References}

Aguilar-Farias, N., Cortinez-O’Ryan, A., Sadarangani, K. P., Von Oetinger, A., Leppe, J., Valladares, M., . . . Cristi-Montero, C. (2016). Results From Chile’s 2016 Report Card on Physical Activity for Children and Youth. J Phys Act Health, 13(11 Suppl 2), S117S123. doi:10.1123/jpah.2016-0314

Aguilar-Farias, N., Martino-Fuentealba, P., Carcamo-Oyarzun, J., Cortinez-O’Ryan, A., Cristi-Montero, C., Von Oetinger, A., \& Sadarangani, K. P. (2018). A regional vision of physical activity, sedentary behaviour and physical education in adolescents from Latin America and the Caribbean: results from 26 countries. Int $J$ Epidemiol, 47(3), 976-986. doi:10.1093/ije/dyy033

Aguilar-Farias, N., Martino-Fuentealba, P., \& Espinoza-Silva, M. (2015). Objectively Measured Physical Activity and Sedentary Behaviour Patterns in Chilean Pre-School Children. Nutr Hosp, 32(6), 26062612. doi:10.3305/nh.2015.32.6.9489

Barkley, J. E., Rebold, M., Carnes, A., Glickman, E. L., \& Kobak, M. (2014). The validity of a commercially-available, low-cost, wristmounted accelerometer during treadmill exercise. Med Sci Sports Exerc, 46(5S), 485-508. doi:10.1249/01.mss.0000451199.18393.fd

Bauman, A. E., Reis, R. S., Sallis, J. F., Wells, J. C., Loos, R. J. F., \& Martin, B. W. (2012). Correlates of physical activity: why are some people physically active and others not? Lancet, 380(9838), 258-271. doi:10.1016/s0140-6736(12)60735-1

Beck, J., Chard, C. A., Hilzendegen, C., Hill, J., \& Stroebele-Benschop, N. (2016). In-school versus out-of-school sedentary behavior patterns in U.S. children. BMCobesity, 3, 34. doi:10.1186/s40608016-0115-3

Beltrán Carrillo, V. J., Sierra, A. C., Jiménez Loais, A., González-Cutre, D., Martínez Galindo, C., \& Cervelló, E. (2017). Diferencias según género en el tiempo empleado por adolescentes en actividad sedentaria y actividad física en diferentes segmentos horarios del día. RETOS. Nuevas Tendencias en Educación Física, Deporte y Recreación(31).

Brooke, H. L., Corder, K., Griffin, S. J., \& van Sluijs, E. M. (2014). Physical activity maintenance in the transition to adolescence: a longitudinal study of the roles of sport and lifestyle activities in British youth. PloS one, 9(2), e89028. doi:10.1371/ journal.pone.0089028

Butte, N. F., Ekelund, U., \&Westerterp, K. R. (2012).Assessing physical activity using wearable monitors: measures of physical activity. Med Sci Sports Exerc, 44(1 Suppl 1), S5-12. doi:10.1249/ MSS.0b013e3182399c0e

Carcamo-Oyarzun, J., Wydra, G, Hernandez-Mosqueira, C., \& Salazar, C. M. (2017). Actitudes hacia la educación física: Grados de importancia y conformidad según escolares de Chile y Alemania. Una mirada intercultural. Retos: nuevas tendencias en educación física, deportey recreación(32), 158-162.

Cortinez-O’Ryan,A., Albagli, A., Sadarangani, K. P., \& Aguilar-Farias, N. (2017). Reclaiming streets for outdoor play: A process and impact evaluation of «Juega en tu Barrio» (Play in your Neighborhood), an intervention to increase physical activity and opportunities for play. PloS one, 12(7), e0180172. doi:10.1371/ journal.pone.0180172

Cox, M., Schofield, G., Greasley, N., \& Kolt, G. S. (2006). Pedometer steps in primary school-aged children: a comparison of schoolbased and out-of-school activity. J Sci Med Sport, 9(1-2), 91-97. doi:10.1016/j.jsams.2005.11.003

Craig, C. L., Cameron, C., Griffiths, J. M., \& Tudor-Locke, C. (2010) Descriptive epidemiology of youth pedometer-determined physical activity: CANPLAY. Med Sci Sports Exerc, 42(9), 1639-1643. doi:10.1249/MSS.0b013e3181d58a92

Cristi-Montero, C. (2013). [Is it enough to recommend to patients take a walk? Importance of the cadence]. Nutr Hosp, 28(4), 1018-1021. doi:10.3305/nh.2013.28.4.6543 da Silva, I. C. M., van Hees, V.T., Ramires, V. V., Knuth, A. G., Bielemann, R. M., Ekelund, U., ... Hallal, P. C. (2014). Physical activity levels in three Brazilian birth cohorts as assessed with raw triaxial wrist accelerometry. Int J Epidemiol, 43(6), 1959-1968. doi:10.1093/ije/ dyu203

Deforche, B., De Bourdeaudhuij, I., D’Hondt, E., \& Cardon, G. (2009). Objectively measured physical activity, physical activity related personality and body mass index in 6- to 10-yr-old children: a cross-sectional study. Int J Behav Nutr Phys Act, 6, 25. doi:10.1186/ 1479-5868-6-25

DiMaggio, C., Frangos, S., \& Li, G. (2016). National Safe Routes to School program and risk of school-age pedestrian and bicyclist injury. Ann Epidemiol, 26(6), 412-417. doi:10.1016/ j.annepidem.2016.04.002

Dorsey, K. B., Herrin, J., \& Krumholz, H. M. (2011). Patterns of moderate and vigorous physical activity in obese and overweight compared with non-overweight children. Int J Pediatr Obes, 6(22), e547-555. doi:10.3109/17477166.2010.490586

Dumith, S. C., Gigante, D. P., Domingues, M. R., \& Kohl, H. W., 3rd. (2011). Physical activity change during adolescence: a systematic review and a pooled analysis. Int J Epidemiol, 40(3), 685-698. doi:10.1093/ije/dyq272

Duncan, M. J., Al-Nakeeb, Y., Woodfield, L., \& Lyons, M. (2007). Pedometer determined physical activity levels in primary school children from central England. Prev Med, 44(5), 416-420. doi:10.1016/j.ypmed.2006.11.019

Fadel, A. C., Weiss, P. S., Meyer, A., Kay, C., Allensworth, D., Green, K., . . Gazmararian, J. A. (2015). Validation of Physical Activity Measuring Devices in Children. Res Q Exerc Sport, 86(2S), A13. doi:http://dx.doi.org/10.1080/02701367.2015.1049504

Gao, Y., Wang, J.-j., Lau, P. W. C., \& Ransdell, L. (2015). Pedometerdetermined physical activity patterns in a segmented school day among Hong Kong primary school children. JExerc Sci Fit, 13(1), 42-48. doi:http://dx.doi.org/10.1016/j.jesf.2015.03.002

Godard, C., Román, M., Rodríguez, M. D. P., Leyton, B., \& Salazar, G (2012). Variabilidad de la actividad física en niños chilenos de 4 a 10 años: estudio por acelerometría. Arch Argent Pediatr, 110(5), 388393.

Goodman, A., Page, A. S., Cooper, A. R., \& International Children's Accelerometry Database, C. (2014). Daylight saving time as a potential public health intervention: an observational study of evening daylight and objectively-measured physical activity among 23,000 children from 9 countries. Int J Behav Nutr Phys Act, 11, 84 . doi:10.1186/1479-5868-11-84

Hallal, P. C., Andersen, L. B., Bull, F. C., Guthold, R., Haskell, W., Ekelund, U., \& Lancet Physical Activity Series Working, G. (2012). Global physical activity levels: surveillance progress, pitfalls, and prospects. Lancet, 380(9838), 247-257. doi:10.1016/S01406736(12)60646-1

Hyndman, B. P., Benson, A. C., Ullah, S., \& Telford, A. (2014). Evaluating the effects of the Lunchtime Enjoyment Activity and Play (LEAP) school playground intervention on children's quality of life, enjoyment and participation in physical activity. BMC Public Health, 14(1), 164. doi:10.1186/1471-2458-14-164

Jago, R., Salway, R., Lawlor, D. A., Emm-Collison, L., Heron, J., Thompson, J. L., \& Sebire, S. J. (2018). Profiles of children's physical activity and sedentary behaviour between age 6 and 9: a latent profile and transition analysis. Int J Behav Nutr Phys Act, 15(1), 103. doi:10.1186/s12966-018-0735-8

Janssen, I., \& Leblanc, A. G. (2010). Systematic review of the health benefits of physical activity and fitness in school-aged children and youth. Int J Behav Nutr Phys Act, 7, 40. doi:10.1186/1479-5868-740

Katzmarzyk, P. T., Barreira, T. V., Broyles, S. T., Champagne, C. M., Chaput, J. P., Fogelholm, M., . . . Church, T. S. (2015). Physical Activity, Sedentary Time, and Obesity in an International Sample 
of Children. Med Sci Sports Exerc, 47(10), 2062-2069. doi:10.1249/ MSS.0000000000000649

Kolle, E., Steene-Johannessen, J., Andersen, L. B., \& Anderssen, S. A. (2009). Seasonal variation in objectively assessed physical activity among children and adolescents in Norway: a cross-sectional study. Int J Behav Nutr Phys Act, 6, 36. doi:10.1186/1479-5868-6-36

Leinaar, E., Alamian,A., \& Wang, L. (2016). Asystematic review of the relationship between asthma, overweight, and the effects of physical activity in youth. Ann Epidemiol, 26(7), 504-510 e506. doi:10.1016/ j.annepidem.2016.06.002

Medina, C., Barquera, S., Katzmarzyk, P. T., \& Janssen, I. (2015). Physical activity during recess among 13-14 year old Mexican girls. BMC pediatrics, 15, 17. doi:10.1186/s12887-015-0329-4

Moreno, L., Cano, M., Orellana, Y., \& Kain, J. (2015). Compliance of physical activity guidelines by chilean low-income children: difference between school and weekend days and nutritional status. Nutr Hosp, 31(5), 2195-2201. doi:10.3305/nh.2015.31.5.8058

Parra Saldías, M. E., Vega, D. M., Fernández, I. L., \& Ramírez, J. V. (2018). How many daily steps are really enough for adolescents? A cross-validation study. Retos: nuevas tendencias en educación física, deporte y recreación(33), 241-246.

Rhodes, R. E., \& Smith, N. E. I. (2006). Personality correlates of physical activity: a review and meta analysis. Br J Sports Med, 40(12), 958-965. doi:10.1136/bjsm.2006.028860

Rich, C., Geraci, M., Griffiths, L., Sera, F., Dezateux, C., \& CortinaBorja, M. (2013). Quality control methods in accelerometer data processing: defining minimum wear time. PloS one, 8(6), e67206. doi:10.1371/journal.pone.0067206

Rosa, C. S. d. C., Messias, K. P., Fernandes, R. A., Silva, C. B. d., Monteiro, H. L., \& Freitas Júnior, I. F. (2011). Atividade física habitual de crianças e adolescentes mensurada por pedômetro e sua relação com índices nutricionais. Rev Bras Cineantropom Desempenho Hum, 13, 22-28.

Rowlands, A. V., \& Eston, R. G. (2005). Comparison of accelerometer and pedometer measures of physical activity in boys and girls, ages 8-10 years. Res Q Exerc Sport, 76(3), 251-257. doi:10.1080/

\subsubsection{6}

Steele, R. M., van Sluijs, E. M. F., Sharp, S. J., Landsbaugh, J. R., Ekelund, U., \& Griffin, S. J. (2010). An investigation of patterns of children's sedentary and vigorous physical activity throughout the week. Int J Behav Nutr Phys Act, 7(1), 1-8. doi:10.1186/14795868-7-88

Steinbeck, K. S. (2001). The importance of physical activity in the prevention of overweight and obesity in childhood: a review and an opinion. Obes Rev, 2(2), 117-130. doi:10.1046/j.1467789x.2001.00033.x

Strath, S. J., Pfeiffer, K. A., \& Whitt-Glover, M. C. (2012).Accelerometer use with children, older adults, and adults with functional limitations. Med Sci Sports Exerc, 44(1 Suppl 1), S77-85. doi:10.1249/ MSS.0b013e3182399eb1

Strong, W. B., Malina, R. M., Blimkie, C. J., Daniels, S. R., Dishman, R. K., Gutin, B., . . . Trudeau, F. (2005). Evidence based physical activity for school-age youth. J Pediatr, 146(6), 732-737. doi:10.1016/j.jpeds.2005.01.055

Tandon, P. S., Tovar, A., Jayasuriya, A. T., Welker, E., Schober, D. J., Copeland, K., . . . Ward, D. S. (2016). The relationship between physical activity and diet and young children's cognitive development: A systematic review. Prev Med Rep, 3, 379-390. doi:10.1016/j.pmedr.2016.04.003

Tucker, P., \& Gilliland, J. (2007). The effect of season and weather on physical activity: A systematic review. Public Health, 121(12), 909-922. doi:http://dx.doi.org/10.1016/j.puhe.2007.04.009

Vander Ploeg, K. A., Wu, B., McGavock, J., \& Veugelers, P. J. (2012). Physical activity among Canadian children on school days and nonschool days. J Phys Act Health, 9(8), 1138-1145.

Westerterp, K. R., \& Plasqui, G. (2004). Physical activity and human energy expenditure. Curr Opin Clin Nutr Metab Care, 7(6), 607613.

World Health Organization. Growth reference 5-19 years. Retrieved from http:/www.who.int/growthref/who2007_bmi_for_age/en/

World Health Organization. (2010). Global recommendations on physical activity for health. Retrieved from Geneva, Switzerland:

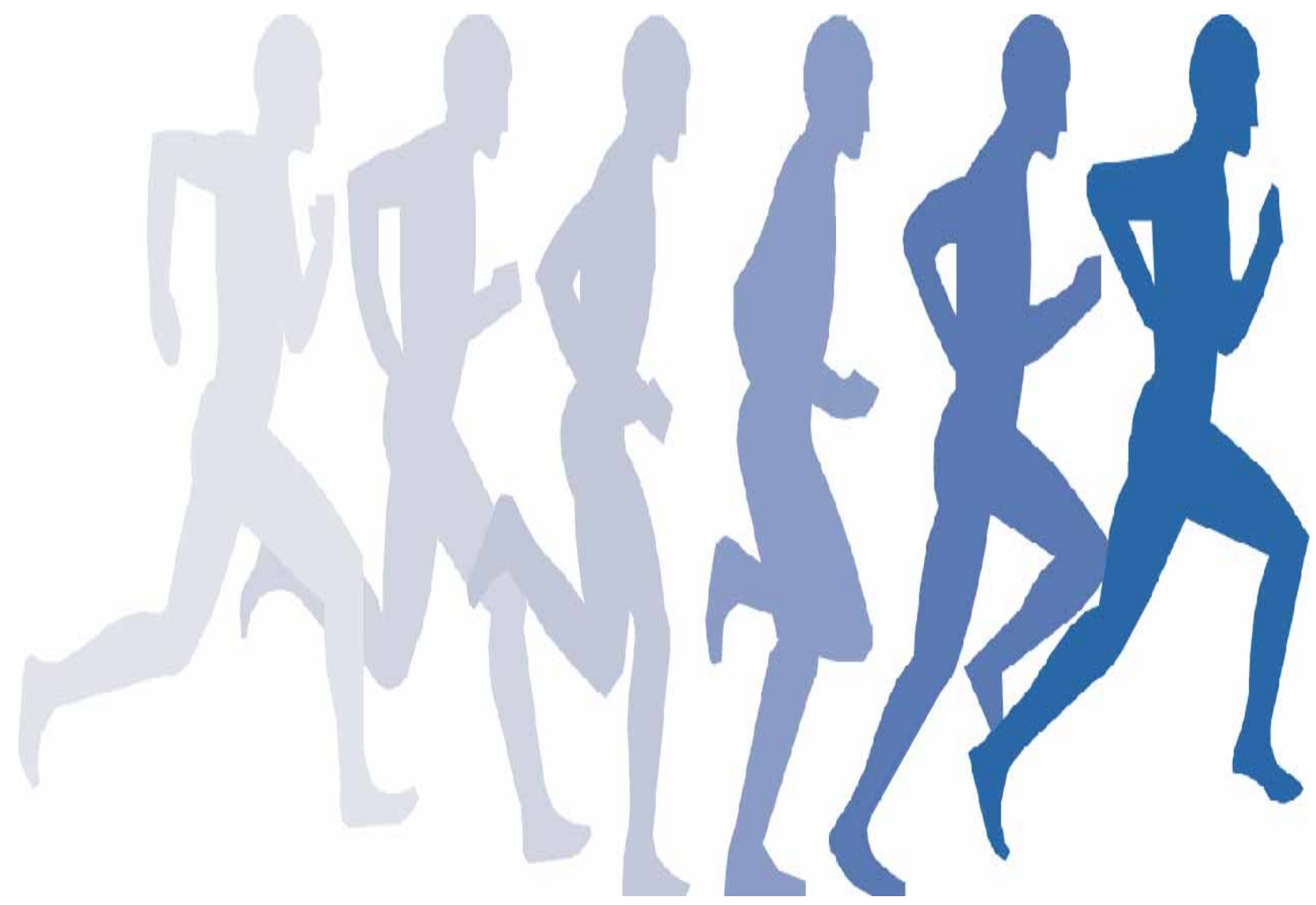

